\title{
Citrus Responses to Xylella fastidiosa Infection
}

A. L. Garcia, S. C. Z. Torres, and M. Heredia, Universidade de Ribeirão Preto, Av. Costábile Romano, 2.201, Ribeirão Preto, SP, 14096-900, Brazil; and S. A. Lopes, Fundo de Defesa da Citricultura, Av. Dr. Adhemar Pereira de Barros, 201, Araraquara, SP, 14.807040, Brazil

\begin{abstract}
Garcia, A. L., Torres, S. C. Z., Heredia, M., and Lopes, S. A. 2012. Citrus responses to Xylella fastidiosa infection. Plant Dis. 96:1245-1249.

The xylem-limited bacterium Xylella fastidosa causes the widely disseminated citrus variegated chlorosis disease (CVC). In Brazil, CVC has been known for more than 20 years and affects only sweet orange. Lime and mandarin have remained free of symptoms despite the high inoculum pressure. Knowing the mechanisms underlying this apparent resistance is important to devise new disease control strategies. The reaction of commercial sweet orange ('Caipira', 'Natal', 'Pêra', and 'Valencia'), lime (Mexican and Persian), mandarin ('Cleopatra', 'Cravo', 'Ponkan', and 'Sunki'), and the acid citrus species Rangpur to $X$. fastidiosa was compared in artificially inoculated seedlings, which were

assessed for symptom expression, pathogen isolation, and the amount of apparently occluded xylem vessels in cross-sectioned leaf petioles. Only the sweet orange expressed typical CVC symptoms, varying from $53.8 \%$ in Valencia to $63.0 \%$ in Caipira. Average percentages of positive isolations $(p i)$ and occluded vessels $(o v)$ were higher in sweet orange ( $p i$ $=59.2$ to $75.0 ; \mathrm{ov}=10.7$ to 25.8$)$ than mandarin $(p i=2.3$ to $16.3 ; \mathrm{ov}=$ 1.4 to 4.0 ), lime ( $p i=0$ to $5.4 ; o v=0$ to 2.1 ), or Rangpur ( $p i=1,9 ; o v=$ 1.1). There were no obvious differences in xylem anatomy among all citrus varieties, suggesting that the mechanisms of resistance to CVC are not related to any physical variation in xylem structure.
\end{abstract}

Citrus variegated chlorosis (CVC), caused by the xylem-limited and insect-transmitted bacterium Xylella fastidiosa, is a damaging disease to citrus. It affects yield by reducing the size, quality, and weight of the fruit (1) and the economic lifespan of the affected trees. Symptom progression is faster in younger than in older trees. Increases in the incidence of younger affected trees in citrus orchards also may be fast. In an 18-month-period, the incidences of symptomatic trees increased from 2.8 to $87.9,11.4$ to 98 , and 0 to $13.6 \%$ in three blocks in a farm located in Bebedouro, SP (8). The success in disease control depends on how rigorously the recommended measures are implemented, which include the use of healthy trees for planting, elimination or pruning of symptomatic trees, and insecticide applications to reduce vector populations. Pruning is recommended only for trees older than 3 years of age while expressing the very initial CVC symptoms; namely, variegated chlorosis on leaves located at the tip of a single branch. It has been estimated that 6 million trees have been eliminated in recent years in the state of São Paulo, where the overall disease incidence reached $40.3 \%$ in 2011 (4).

In Brazil, CVC was first reported in 1987 in Macaubal municipality located in the northern São Paulo state (19). In the last two decades, CVC symptoms have been observed only in sweet orange. Lime, lemon, mandarin, and Murcott tangor have remained free of symptoms despite their proximity to highly affected sweet orange orchards and the presence of the insect vectors $(18,23)$. Because no obvious feeding preference for one or the other citrus variety or species has been observed among the vectors (P. T. Yamamoto, unpublished data), a high probability existed that all citrus varieties would be exposed to CVC-infectious insect vectors.

A previous study using graft inoculation of a hybrid population of mandarin seedlings showed that the inoculated seedlings re-

Corresponding author: S. A. Lopes, E-mail: slopes@ fundecitrus.com.br

Accepted for publication 25 February 2012.

http://dx.doi.org/10.1094/PDIS-10-11-0868-RE

(C) 2012 The American Phytopathological Society mained asymptomatic for the 29-month evaluation period (21). A better understanding of the responses of lime and mandarin to $X$. fastidiosa infection may be useful to develop new strategies for CVC management as, for example, in developing cultivars or transgenic trees that resist $X$. fastidiosa infection. Our objectives were to characterize the responses of 11 citrus varieties to $X$. fastidiosa infection under greenhouse conditions.

\section{Materials and Methods}

Plants and inoculation. Fruit of the acid citrus species Rangpur (Citrus limonia Osbeck); Mexican (C. aurantifolia Swingle) and Persian (C. limettioides L.) lime; mandarin 'Sunki' (C. sunki Hort. ex. Tan.), 'Cleopatra' (C. reshni Hort. ex. Tan), 'Ponkan' (C. reticulata Blanco), and 'Cravo' ( $C$. limonia Osbeck); and sweet orange 'Valencia', 'Pêra', 'Caipira', and 'Natal' (C. sinensis L.) were collected from healthy trees growing in the germplasm bank of the Centro APTA Citros "Sylvio Moreira", Cordeirópolis, SP, and from a rootstock collection of the Cambuhy Farm, Matão, SP. Seeds were germinated in 15-liter pots containing Plantmax citrus substrate (Paulínia, SP). Thirty days later, the seedlings were carefully removed from the pots, placed on a paper towel over a bench, and inoculated by injecting a phosphate-buffered saline (PBS) suspension prepared from a 10-day-old culture of $X$. fastidiosa containing $10^{9} \mathrm{CFU} / \mathrm{ml}$ with a syringe and insulin needle at the stem, as previously described (12). Thirty seedlings each of Cleopatra mandarin, Mexican lime, and Caipira sweet orange and 60 seedlings each of all the remaining materials were injected with the $X$. fastidiosa suspensions, and 12 seedlings each of all materials were injected with PBS alone as controls. The seedlings were transferred immediately to 72-cell foam trays containing Plantmax citrus mixed with Basacote Plus (Compo, Münster, Germany), 20 $\mathrm{g} / \mathrm{liter}$, and maintained in a greenhouse with a cooling system that did not allow the air temperature to exceed $32^{\circ} \mathrm{C}$. The seedlings were irrigated twice a day and further treated with a foliar application of a nitrogen fertilizer (NPK, 10:10:10) when leaves started to exhibit a general chlorosis symptom.

Symptom evaluations. Every 2 months, from 2 to 12 months post inoculation, the seedlings were assessed for the presence of chlorosis or typical CVC symptoms on the leaves. Symptom sever- 
ity was assessed based on the percentage of leaves showing symptoms per plant.

X. fastidiosa culture. Ten months after inoculation, samples were collected and processed from all seedlings in attempts to recover $X$. fastidiosa in phosphate charcoal yeast extract (PCYE) agar (13). A second attempt was made 2 weeks later from those seedlings that tested negative or those that were heavily contaminated with other bacteria in the first culturing attempt. Leaf petioles and main veins of the four leaves most distal to the inoculation site were disinfested in sodium hypochlorite, washed twice in sterile water, and macerated in PBS. The macerated saps were serially diluted five times and aliquots of $20 \mu \mathrm{l}$ of each dilution were spread on the surface of PCYE agar plates (13). The plates were transferred to an incubator and maintained at $28^{\circ} \mathrm{C}$ in the dark for 30 days before the colonies were counted. The titer, in CFU per gram of tissue, was then estimated based on CFU number, dilution factor, and the average weight of the samples.

Microscopy of leaf petioles. Three leaves, positioned at the middle portion of the plant, were removed from one to four inoculated (symptomatic or asymptomatic) and four control seedlings per citrus variety 12 months post inoculation. The petioles were separated, fixed in a solution of formaldehyde-glacial acetic acidethanol (6), dehydrated in serial concentrations of ethanol, embedded in paraffin, and cut in several sections, $5 \mu \mathrm{m}$ in thickness, in a rotary microtome (Leica RM 2125RT). Sections not damaged during cutting process were selected, treated in a 9:1 (vol/vol) solution of safranine-Astra blue $1 \%$, and mounted in microscope slides using Alklan synthetic resin (Alkimia, São José dos Campos, Brazil). The plates were observed with a Nikon Eclipse E600 (Nikon, Tokyo) microscope and 2- and 40-fold amplified images were captured using a JVC TK C1380 image capture system (JVC, Kanagawa, Japan). The 40-fold amplified images were then analyzed using the ImageJ Launcher 1.44 software (http://rsb.info.nih. gov/ij). Free and apparently occluded xylem vessels were counted from 5 arbitrarily selected fields per seedling, totaling 20 fields per treatment or 40 fields per citrus variety.

\section{Results}

Symptom development. Most seedlings survived the inoculation procedure, including those injected with PBS alone (97.3\%) and those with $X$. fastidiosa cell suspension in PBS (94.4\%). On the survived $X$. fastidiosa-inoculated seedlings, leaf symptoms typical of CVC developed only on sweet orange (Fig. 1). They started as yellow chlorotic spots observed about 4 months after inoculation. The small brown gummy spots, usually observed on the lower side of the leaf and in the center of the chlorotic spots, appeared approximately 2 months later. The leaves of Sunki mandarin also developed chlorotic lesions but they were much less intense than those on sweet orange and no gummy spots were de- tected on the lower side. No symptom developed on the PBSinoculated controls or on any of the inoculated plants of mandarin, lime, or the acid citrus species Rangpur (Tables 1 and 2). The percentage of symptomatic seedlings increased over time. They progressed faster and reached the highest value in Caipira (63.0\%) 10 months post inoculation, followed by Natal (55.6\%), Pêra (58.6\%), Valencia $(53,8 \%)$, and Sunki $(40.7 \%)$, two more months later (Tables 1 and 2). Pêra showed the highest percentage of symptomatic leaves at $45.9 \%$ per plant, followed by Caipira (39.1\%), Valencia (33.9\%), Natal (30.1\%), and Sunki (15.9\%).

$X$. fastidiosa culture. $X$. fastidiosa was recovered in culture media from most citrus tested but at variable percentages and at variable titers, depending on the citrus variety and on the status of the leaf (Table 3). With the exception of Sunki mandarin, the values for these parameters were significantly higher for the plants showing symptoms. In sweet orange, the respective values of positive isolations and cell titers, in log CFU per gram of tissue (CFU), varied from 70.3 to $100 \%$ and 6.7 to $7.0 \mathrm{CFU}$ for the symptomatic and from 16.7 to $28.6 \%$ and 4.4 to $6.5 \mathrm{CFU}$ for the asymptomatic plants. In Sunki, positive isolations and titers were $16.7 \%$ and 5.4 CFU for the symptomatic and $20.0 \%$ and $5.7 \mathrm{CFU}$ for the asymptomatic plants. For the remaining citrus not expressing any symptoms, the percentage of positive isolations varied from $1.8 \%$ and 6.3 CFU in Rangpur to $15.4 \%$ and $6.7 \mathrm{CFU}$ in Mexican lime. $X$. fastidiosa was not recovered from any plant of Persian lime.

Microscopy of leaf petioles. The microscopy procedure allowed clear observation of the distinct cell layers found in cross sections of the leaf petioles, including the epidermis, parenchyma, collenchyma, sclerenchyma, phloem, xylem, and medulla (Fig. 2), with no detectable differences in the number of xylem vessels, cell for-

Table 2. Cumulative responses of commercial citrus varieties to Xylella fastidiosa inoculation ${ }^{2}$

\begin{tabular}{lccc}
\hline Citrus variety & $\begin{array}{c}\text { Symptomatic } \\
\text { seedlings }(\%)\end{array}$ & $\begin{array}{c}\text { Positive } \\
\text { isolations }(\%)\end{array}$ & $\begin{array}{c}\text { Occluded } \\
\text { vessels }(\%)\end{array}$ \\
\hline Caipira sweet orange & $63.0 \mathrm{a}$ & $75.0 \mathrm{a}$ & $10.7 \mathrm{bc}$ \\
Natal sweet orange & $55.9 \mathrm{a}$ & $60.3 \mathrm{a}$ & $18.0 \mathrm{ab}$ \\
Pêra sweet orange & $58.7 \mathrm{a}$ & $59.2 \mathrm{a}$ & $25.8 \mathrm{a}$ \\
Valencia sweet orange & $53.8 \mathrm{a}$ & $66.7 \mathrm{a}$ & $20.8 \mathrm{ab}$ \\
Sunki mandarin & $40.9 \mathrm{a}$ & $16.3 \mathrm{~b}$ & $1.4 \mathrm{c}$ \\
Ponkan mandarin & $0 \mathrm{~b}$ & $2.3 \mathrm{c}$ & $2.9 \mathrm{c}$ \\
Cleopatra mandarin & $0 \mathrm{~b}$ & $10.0 \mathrm{bc}$ & $4.0 \mathrm{c}$ \\
Cravo mandarin & $0 \mathrm{~b}$ & $7.4 \mathrm{bc}$ & $3.6 \mathrm{c}$ \\
Mexican lime & $0 \mathrm{~b}$ & $15.4 \mathrm{bc}$ & $2.1 \mathrm{c}$ \\
Persian lime & $0 \mathrm{~b}$ & $0 \mathrm{c}$ & $0 \mathrm{c}$ \\
Rangpur & $0 \mathrm{~b}$ & $1.9 \mathrm{c}$ & $1.1 \mathrm{c}$ \\
$F$ test & 164.28 & 39.42 & 10.63 \\
\hline${ }^{z}$ Means followed by different letters within the columns are significantly \\
different $(P<0.01)$
\end{tabular}

Means followed by different letters within the columns are significantly different $(P<0.01)$.

Table 1. Incidence of sweet orange, mandarin, and lime exhibiting citrus variegated chlorosis (CVC) symptoms $6,8,10$, and 12 months after the seedlings were inoculated with a cell suspension of Xylella fastidiosa

\begin{tabular}{|c|c|c|c|c|c|c|}
\hline \multirow[b]{2}{*}{ Citrus variety } & \multirow[b]{2}{*}{ Use $^{y}$} & \multirow[b]{2}{*}{ Total $^{\mathbf{z}}$} & \multicolumn{4}{|c|}{ Number of seedlings expressing CVC symptoms $(\%)^{x}$} \\
\hline & & & 6 months & 8 months & 10 months & 12 months \\
\hline Caipira sweet orange & Scion & 27 & $2(7.4)$ & 8 (29.6) & $17(63.0)$ & $17(63.0)$ \\
\hline Natal sweet orange & Scion & 54 & $6(11.1)$ & $16(29.6)$ & $25(46.3)$ & $30(55.6)$ \\
\hline Pêra sweet orange & Scion & 58 & $2(3.4)$ & $13(22.4)$ & $30(51.7)$ & $34(58.6)$ \\
\hline Valencia sweet orange & Scion & 52 & $4(7.7)$ & $6(11.5)$ & $25(48.1)$ & $28(53.8)$ \\
\hline Sunki mandarin & Rootstock & 59 & $5(8.5)$ & $9(15.3)$ & $22(37.3)$ & $24(40.7)$ \\
\hline Ponkan mandarin & Scion & 52 & 0 & 0 & 0 & 0 \\
\hline Cleopatra mandarin & Rootstock & 29 & 0 & 0 & 0 & 0 \\
\hline Cravo mandarin & Rootstock & 59 & 0 & 0 & 0 & 0 \\
\hline Mexican lime & Scion & 30 & 0 & 0 & 0 & 0 \\
\hline Persian lime & Scion & 59 & 0 & 0 & 0 & 0 \\
\hline Rangpur & Rootstock & 59 & 0 & 0 & 0 & 0 \\
\hline
\end{tabular}

${ }^{x}$ Number and percentage of seedlings expressing typical CVC symptoms (yellow chlorotic spot on upper leaf surface plus small gummy spots at the opposite side) at different time periods after inoculation.

${ }^{y}$ Use in the field.

${ }^{\mathrm{z}}$ Total inoculated seedlings $=$ number of surviving seedlings. 
mat, and structure found among the citrus varieties when cross sections of leaf petioles of the control seedlings were considered (Table 4).

The microscopy procedure also allowed clear separation between free and apparently occluded xylem vessels. Occluded vessels were filled with an unknown substance, resulting in dark blue coloration after staining. Occluded vessels were observed on leaves of inoculated as well as PBS-inoculated plants (Table 4). In PBSinoculated plants, the occlusion usually occupied only part of the xylem lumen, no crystals were present, and the average numbers of occluded vessels were low, varying from 0.2 to 1.8 , with no significant differences among the varieties tested. In the inoculated plants, the occlusion occupied, in general, most of the lumen extension, the color of the occluding substance was more intense, crystals could be present, and the percentages of occluded vessels were significantly higher. In symptomatic plants, they varied from $10.7 \%$ in Caipira to $25.8 \%$ in Pêra sweet orange and averaged $1.4 \%$ in Sunki mandarin. In asymptomatic seedlings, they varied from $1.1 \%$ in Cravo to $4.0 \%$ in Cleopatra mandarin (Table 4).

Statistical analysis summarized in Table 2 showed high and positive correlations between the percentages of occluded vessels with those of symptomatic plants $\left(R^{2}=0.79, P<0.01\right)$ and with those of positive $X$. fastidiosa isolations $\left(R^{2}=0.84, P<0.01\right)$. Statistically positive correlations also were observed between the percentages of symptomatic plants with those of positive isolations $\left(R^{2}=0.93, P<0.01\right)$.

\section{Discussion}

In this work, the resistance of 11 commercial citrus varieties to $X$. fastidiosa infection was characterized based on the percentage of seedlings that expressed leaf symptom $6,8,10$, and 12 months after inoculation; populations of cultivable bacteria from symptomatic and asymptomatic seedlings; and the percentage of apparently obstructed xylem vessels.

The seedlings expressed typical CVC symptoms approximately 6 months after being injected with $X$. fastidiosa cell suspension into the stem of 1-month-old seedlings, which is twice the time observed by Li et al. (9) in graft-inoculated 6-month-old plants. Variations in inoculation procedures, age of the inoculated plants, and inoculum sources may explain these differences.

Typical CVC symptoms developed only in sweet orange. confirming previous work (15) and field observations. The absence of gummy spots in the inoculated seedlings of Sunki mandarin also had been observed in the field, in contrast to the presence of gummy spots that developed on shoots of CVC-affected sweet orange trees (14). However, the chlorosis observed on leaves in the field was similar to that of zinc deficiency, very distinct from the general leaf chlorosis observed in this study. In the field, under natural inoculation conditions, no typical CVC symptoms have been observed on this or any other mandarin; therefore, the result obtained in this work may be a consequence of the artificial inoculation procedure used, favoring the establishment of $X$ fastidiosa infection.
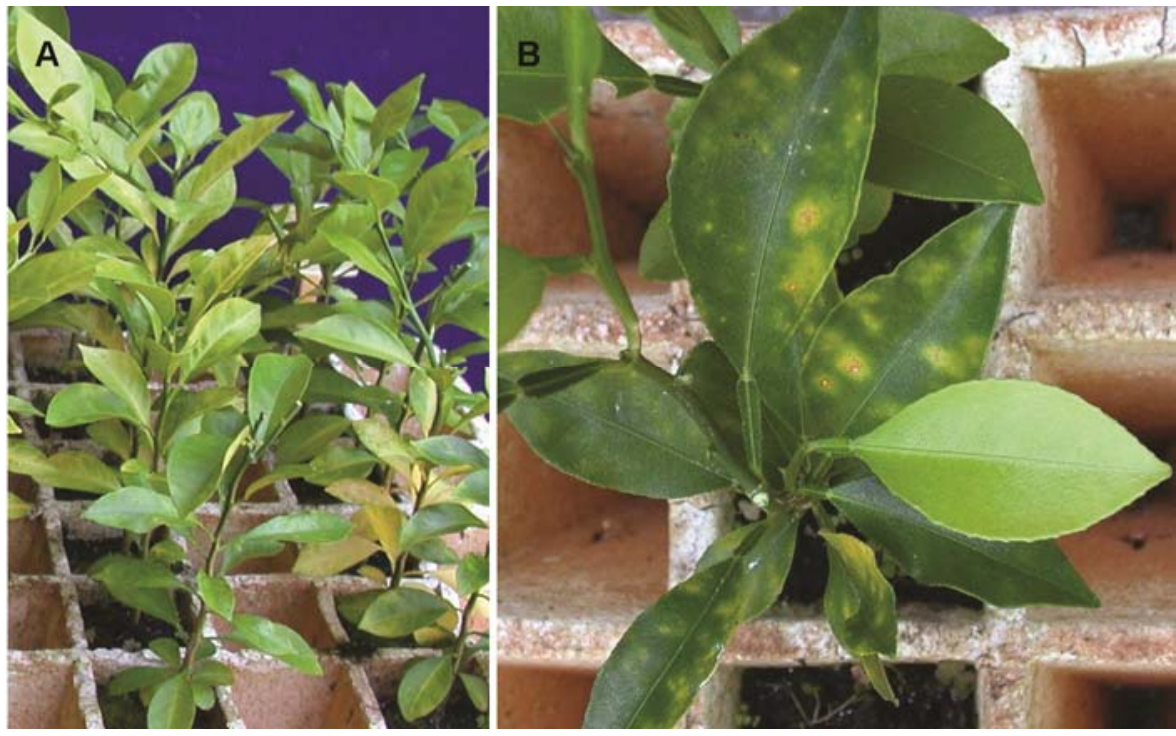

Fig. 1. A, Healthy control and B, Xylella fastidiosa-inoculated sweet orange seedling showing the typical citrus variegated chlorosis symptoms on leaves 6 months after inoculation.
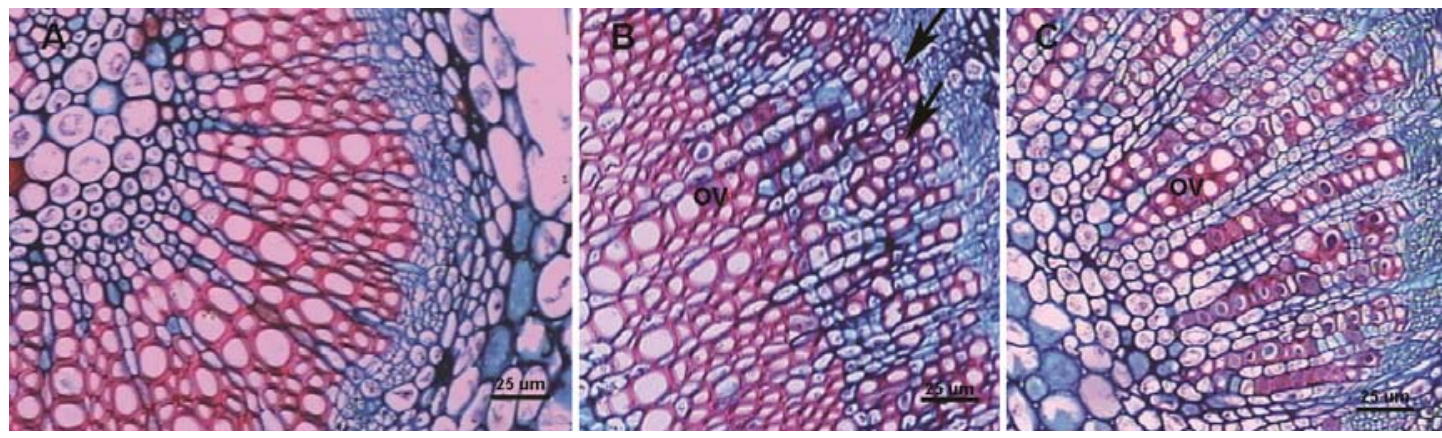

Fig. 2. Enlarged cross-section images of leaf petioles of 'Caipira' sweet orange taken 12 months after inoculation from A, a healthy control and B and C, symptomatic seedlings. Note abnormal xylem cell divisions (arrows) in B and apparently occluded xylem vessels (OV) in both B and C. 
All inoculated sweet orange plants developed typical CVC symptoms, which resemble those induced by mineral deficiencies. Symptom increase was gradual not only in percentage of plants but also in number of symptomatic leaves per plant (data not shown). This pattern of symptom progress might reflect the way $X$. fastidiosa multiplies and colonizes the xylem, gradually obstructing water flow and reducing the plant's uptake of minerals and their availability for plant use (22). The presence in the $X$. fastidiosa genome of genes coding for transmembrane proteins responsible for sequestration of zinc, copper, and other ions reinforces this view. The high and positive correlations between the percentages of apparently blocked vessels, determined 12 months post inoculation, with the percentage of plants showing symptoms, as well as with the percentages of positive $X$. fastidiosa isolations, are additional evidence for the existence of this process in citrus during CVC pathogenesis.

In addition to the images suggesting the presence of substances blocking the sap flow of the xylem in symptomatic leaves, microscopic analysis of petiole cross sections also suggests that CVC pathogenesis involves abnormal cell divisions not only in the $x y-$ lem but also in the cambium and phloem cell layers. This seems to be a common phenomenon in plants affected by $X$. fastidiosa because it also has been detected in coffee (17) and grapevine (3). Abnormal cell divisions, especially of the phloem, are even more prominent in symptomatic leaves of citrus infected with ' $\mathrm{Candida-}$ tus Liberibacter asiaticus' or ' $\mathrm{Ca}$. L. americanus' $(5,7,20)$.

Except for Persian lime, all mandarin, lime, and the acid citrus species Rangpur plants were also colonized by X. fastidiosa, although in low percentages when they were compared with sweet orange. If this phenomenon occurs in the field under natural inoculation conditions, even with plants not necessarily being damaged by the CVC pathogen or showing visible symptons, chances are that those materials could eventually contribute to the CVC epidemics in sweet orange in Brazil. However, field observations and studies on the spatial distribution of CVCaffected trees (8) and on alternative hosts of the CVC pathogen (11) support the hypothesis that no plant species other than affected sweet orange trees would serve as important sources of $X$. fastidiosa to citrus.

The lack of visible differences in xylem anatomy between resistant and susceptible citrus, demonstrated in this study with a considerable number of varieties, had already been observed by Queiroz-Voltan and Paradela Filho (16), who compared the vascular system of adult trees of Rangpur with those of Valencia and Pêra sweet orange. Lack of visible differences in vascular anatomy also was observed in grape cultivars resistant and susceptible to $X$. fastidiosa infection (2), suggesting that the mechanisms underlying resistance to this bacterium, in citrus or grape, are not related to any physical variation in xylem structure. This information may be important for the development of new cultivars or transgenic trees that resist $X$. fastidiosa infection. The demonstration, in this work, that the acid citrus species Rangpur, the rootstock supporting most sweet orange scions in Brazil, is resistant to CVC has already been used to develop a new strategy to control CVC (10).

\section{Acknowledgments}

We thank J. Pompeu, Jr. from Centro de Citricultura Silvio Moreira, Cordeirópolis, SP, for providing seed of citrus; J. C. Barbosa from Universidade Estadual Paulista, Jaboticabal, for statistical analysis of the data; A. Purcell from University of California, Berkeley, and L. W. Timmer, Professor Emeritus, University of Florida, Lake Alfred, for useful suggestions during manuscript

Table 3. Percentage of Xylella fastidiosa-positive isolations from symptomatic and asymptomatic seedlings of sweet orange, mandarin, and lime artificially inoculated with $X$. fastidiosa, 10 months post inoculation

\begin{tabular}{|c|c|c|c|c|}
\hline \multirow[b]{2}{*}{ Citrus variety } & \multicolumn{2}{|c|}{ Positive isolations from symptomatic seedlings } & \multicolumn{2}{|c|}{ Positive isolations from asymptomatic seedlings } \\
\hline & Proportion $(\%)^{y}$ & Cell titer $(\mathbf{S E})^{\mathbf{z}}$ & Proportion $(\%)^{\mathrm{y}}$ & Cell titer $(\mathbf{S E})^{\mathbf{z}}$ \\
\hline Caipira sweet orange & $16 / 17(94.0)$ & $6.7(0.4)$ & 2/7 (28.6) & $4.4(0.1)$ \\
\hline Natal sweet orange & $26 / 30(86.7)$ & $7.0(0.3)$ & $3 / 18(16.7)$ & $6.4(0.8)$ \\
\hline Pêra sweet orange & $26 / 37(70.3)$ & $7.0(0.3)$ & $3 / 12(25.0)$ & $4.7(1.3)$ \\
\hline Valencia sweet orange & $28 / 28(100)$ & $6.9(0.3)$ & $4 / 20(20.0)$ & $6.5(0.9)$ \\
\hline Sunki mandarin & $4 / 24(16.7)$ & $5.4(0.4)$ & $4 / 20(20.0)$ & $5.7(0.3)$ \\
\hline Ponkan mandarin & $\ldots$ & $\ldots$ & $1 / 42(2.4)$ & 5.0 \\
\hline Cleopatra mandarin & $\ldots$ & $\ldots$ & $3 / 30(10.0)$ & $5.5(0.7)$ \\
\hline Cravo mandarin & $\ldots$ & $\ldots$ & $4 / 54(7.4)$ & $6.6(0.9)$ \\
\hline Mexican lime & $\ldots$ & $\ldots$ & $4 / 26(15.4)$ & $6.7(0.8)$ \\
\hline Persian lime & $\ldots$ & $\ldots$ & $0 / 59$ & $\ldots$ \\
\hline Rangpur & $\ldots$ & $\ldots$ & $1 / 55(1.8)$ & 6.3 \\
\hline
\end{tabular}

${ }^{\mathrm{y}}$ Number of seedlings from which $X$. fastidiosa was recovered in phosphate charcoal yeast extract agar medium from the total number of inoculated seedlings and percentage.

${ }^{\mathrm{z}}$ Average cell titer and standard error $(\mathrm{SE})=$ estimated average and range of $\log _{10} X$. fastidiosa CFU per gram of leaf midrib.

Table 4. Average percentages of total and occluded xylem vessels counted in 40K-fold enlarged images of cross sections of healthy leaves of control seedlings and in symptomatic or asymptomatic leaves of Xylella fastidiosa-inoculated seedlings of distinct citrus varieties 12 months after inoculation ${ }^{z}$

\begin{tabular}{|c|c|c|c|c|c|c|c|c|c|}
\hline \multirow[b]{3}{*}{ Citrus variety } & \multicolumn{9}{|c|}{ Average numbers of xylem vessels in petioles of } \\
\hline & \multicolumn{3}{|c|}{ Healthy leaves (control) } & \multicolumn{3}{|c|}{ Symptomatic leaves } & \multicolumn{3}{|c|}{ Asymptomatic leaves } \\
\hline & Total & Occluded & Percent & Total & Occluded & Percent & Total & Occluded & Percent \\
\hline Caipira sweet orange & 83.7 & 0.5 & 0.6 & 82.3 & 9.4 & 10.7 & $\ldots$ & $\ldots$ & $\ldots$ \\
\hline Natal sweet orange & 87.2 & 0.4 & 0.4 & 93.2 & 18.2 & 18.0 & $\ldots$ & $\ldots$ & $\ldots$ \\
\hline Pêra sweet orange & 121.4 & 0.7 & 0.6 & 103.3 & 24.3 & 25.8 & $\ldots$ & $\ldots$ & $\ldots$ \\
\hline Valencia sweet orange & 75.3 & 0.9 & 1.2 & 96.4 & 20.7 & 20.8 & $\ldots$ & $\ldots$ & $\ldots$ \\
\hline Sunki mandarin & 79.3 & 0.5 & 0.7 & 97.3 & 1.5 & 1.4 & $\ldots$ & $\ldots$ & $\ldots$ \\
\hline Ponkan mandarin & 94.5 & 1.7 & 1.8 & $\ldots$ & $\ldots$ & $\ldots$ & 88.7 & 2.6 & 2.9 \\
\hline Cleopatra mandarin & 103.8 & 0.2 & 0.2 & $\ldots$ & $\ldots$ & $\ldots$ & 104.5 & 4.5 & 4.0 \\
\hline Cravo mandarin & 104.2 & 0.5 & 0.5 & $\ldots$ & $\ldots$ & $\ldots$ & 88 & 2.9 & 3.6 \\
\hline Mexican lime & 100.5 & 0.3 & 0.3 & $\ldots$ & $\ldots$ & $\ldots$ & 98.1 & 2.7 & 2.1 \\
\hline Persian lime & 75.8 & 0.3 & 0.3 & $\ldots$ & $\ldots$ & $\ldots$ & $\ldots$ & $\ldots$ & $\ldots$ \\
\hline Rangpur & 94.1 & 0.6 & 0.6 & $\ldots$ & $\ldots$ & $\ldots$ & 91.0 & 0.9 & 1.1 \\
\hline
\end{tabular}

${ }^{\mathrm{z}}$ Values represent the average numbers of 20 fields per healthy, symptomatic, or asymptomatic sample. 
preparation; and Fapesp for financial support to A. L. Garcia during her graduate studies.

\section{Literature Cited}

1. Ayres, A. J. 2000. Intensidade da clorose variegada dos citros em pomares comerciais de laranja do estado de São Paulo e sul do triângulo mineiro. M.S. thesis, Universidade Estadual Paulista, Faculdade de Ciências Agrárias e Veterinárias, Jaboticabal, SP, Brazil.

2. Chatelet, D. S., Wistrom, C. M., Purcell, A. H., Rost, T. L., and Matthews, M. A. 2011. Xylem structure of four grape varieties and 12 alternative hosts to the xylem-limited bacterium Xylella fastidiosa. Ann. Bot. 108:73-85.

3. Esau K. 1948. Anatomic effects of the viruses of Pierce's disease and phony peach. Hilgardia 18:423-82.

4. Fundecitrus-Fundo de defesa da citricultura. 2011. http://www.fundecitrus. com.br.

5. Heredia, M., Garcia, A. L., Torres, S. C. Z., and Lopes, S. A. 2006. Microscopic analysis of leaves of sweet orange trees affected by huanglongbing. In: Proc. Huanglongbing-Greening Int. Workshop 89.

6. Johansen, D. A. 1940. Plant Microtechnique. McGraw-Hill Book Co. Inc., New York.

7. Kim, J. S., Sagaram, U. S., Burns, J. K., Li, J. L., and Wang N. 2009. Response of sweet orange (Citrus sinensis) to 'Candidatus Liberibacter asiaticus' infection: microscopy and microarray analyses. Phytopathology 99:50-57.

8. Laranjeira, F. F., Gottwald, T. R., Amorim, L., Berger, R. D., and Bergamin Filho A. 2000. Spatio-temporal dynamics of citrus variegated chlorosis: a preliminary analysis. Pages 223-231 in: Fourteenth IOCV Conf. InsectTransmitted Procaryotes.

9. Li, W. B., Donadio, L. C., Beretta, M. J. G., Sempionato, O. R., and Miranda, V. S. 1996. Resistance or tolerance of citrus species and cultivars to citrus variegated chlorosis. Pages 216-218 in: Proc. Int. Soc. Citricult. Vol. I.

10. Lopes, S. A., Frare, G. F., Sousa, M. C., Fernandes, N. G., and Ayres, A. J. 2010. A new strategy to control citrus variegated chlorosis disease. Citrus Res. Tech. 31:13.

11. Lopes, S. A., Marcussi, S., Torres, S. C. Z., Souza, V., Fagan, C., and França, S. C. 2003. Weeds as alternative hosts of the citrus, coffee, and plum strains of Xylella fastidiosa in Brazil. Plant Dis. 87:544-549.
12. Lopes, S. A., Teixeira, D. C., Fernandes, N. G., and Ayres, A. J. 2005. An experimental inoculation system to study citrus- Xylella fastidiosa. Plant Dis. 89:250-253.

13. Lopes, S. A., and Torres, S. C. Z. 2006. An effective and low cost medium for isolation of Xylella fastidiosa from citrus and coffee plants. Curr. Microbiol. 53:467-469.

14. Machado, M. A., Silvério, J. L., Baptista, C. R., Cristofani, M., and Teófilo Sobrinho, J. 1992. Avaliação de transmissão e seleção de variedades à CVC. Laranja 13:515-531.

15. Machado, M. A., Silvério, J. L., Baptista, C. R., Laranjeira, F. F., and Beretta, M. J. G. 1993. Avaliação de transmissão e seleção de variedades à Clorose Variegada dos Citros (CVC) II. Laranja 14:167-178.

16. Queiroz-Voltan, R. B., and Paradela Filho, O. 1999. Caracterização de estruturas anatômicas de citros infectados com Xylella fastidiosa. Laranja 20:55-76.

17. Queiroz-Voltan, R. B., Paradela Filho, O., Carelli, M. L. C., and Fahl, J. I. 1998. Aspectos estruturais de cafeeiro infectado com Xylella fastidiosa. Bragantia 57:23-33.

18. Redak, R. A., Purcell, A. H., Lopes, J. R. S., Blua, M. J., Mizell, R. F., and Andersen, P. C. 2004. The biology of xylem fluid feeding insect vectors of Xylella fastidiosa and their relation to disease epidemiology. Annu. Rev. Entomol. 49:243-270.

19. Rosseti, V., Garnier, M., Bové, J. M., Beretta, M. J. G., Teixeira, A. R Quaggio, J. A., and De Negri, J. D. 1990. Présence de bactéries dans le xylème d'orangers atteints de chlorose variégée, une nouvelle maladie des agrumes au Brésil. C. R. Acad. Sci. Paris Ser. III 310:345-349.

20. Schneider, H. 1968. Anatomy of greening diseased sweet orange shoots. Phytopathology 58:1155-1160.

21. Silva, S. R., Oliveira, J. C., Stuchi, E. S., Donadio, L. C., Souza, P. S., and González-Jaimes, E. P. 2004. Avaliação de tangerinas, tangores e tangelos em relação à clorose variegada dos citros. Rev. Bras. Frutic. 26:57-60.

22. Simpson, A. J. G., Reinach, F. C., Arruda, P., et al. 2000. The genome sequence of the plant pathogen Xylella fastidiosa. Nature 406:151-157.

23. Yamamoto, P. T., Felippe, M. R., Caetano, A. C., Sanches, A. L., and Lopes, J. R. S. 2007. First report of Fingeriana dubia Cavichioli transmitting Xylella fastidiosa to citrus. Fitopatol. Bras. 32:3. 